\title{
Public attitude toward urban agriculture in Malaysia: study on values and knowledge in Klang Valley
}

\begin{abstract}
Urban agriculture has drawn attention in Malaysia as a response to economic crisis, food security, and sustainable development. As population grows, the need to provide more jobs and food is becoming more complex both economically and physically. There is no doubt that in Malaysia urban agriculture will play a key role in the livelihood strategies of urban households. The interest in urban agriculture in the country has brought with it the reason to explore public attitude toward getting more involved in this practice. Cross-sectional data were collected, via a structured questionnaire, to gather information on how household values shape attitudes toward urban agriculture. Exploratory factor analysis is used to categorize values, while multiple regression analysis predicts the significant relationship between household knowledge, assigned values, underling values, and household attitude toward urban agriculture. Prior knowledge and values appear, therefore, to significantly shape the attitude of households in Malaysia.
\end{abstract}

Keyword: Attitude; Assigned value; Underlying value; Knowledge; Urban agriculture 